\title{
Schmetterlinge im Palmengarten
}

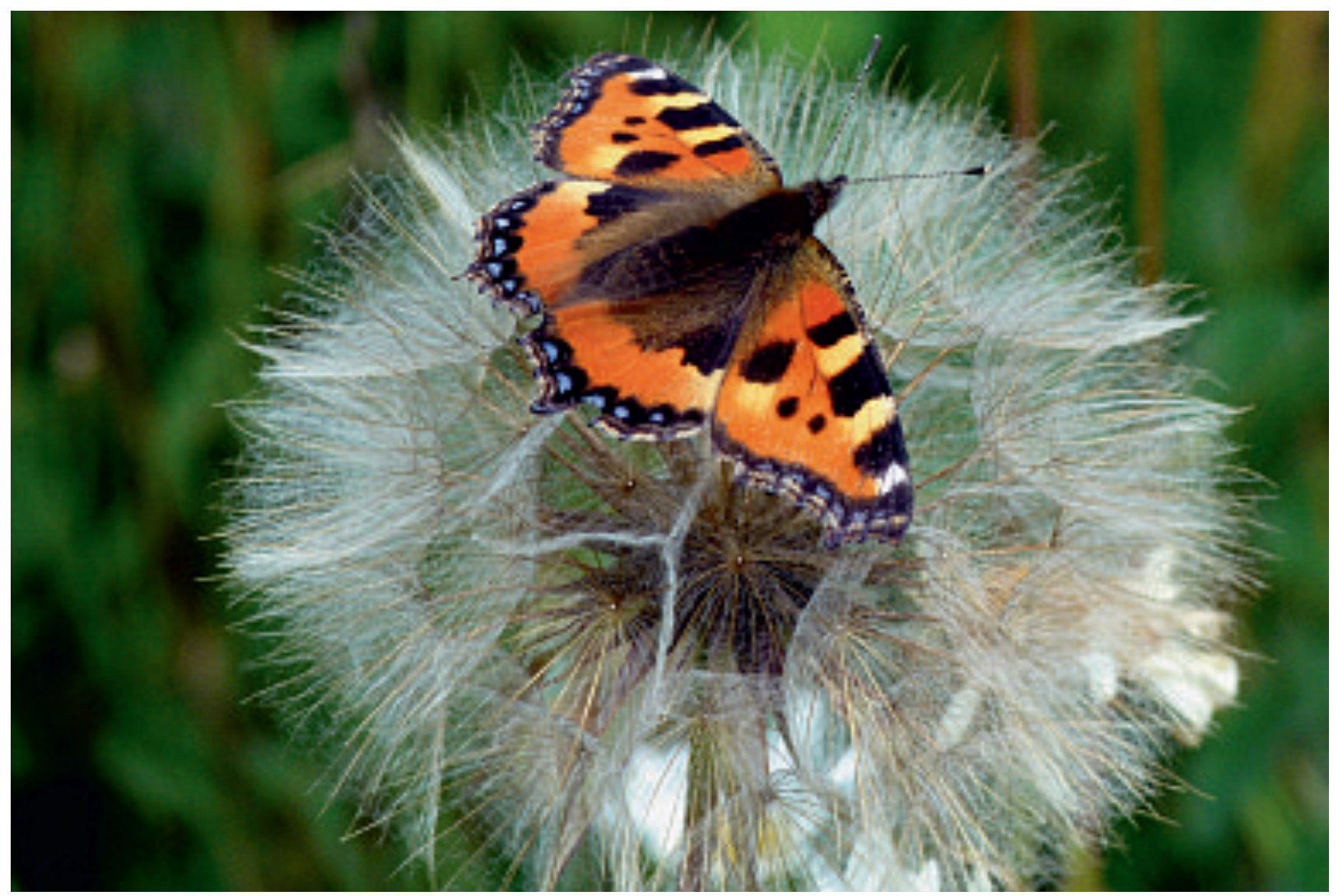

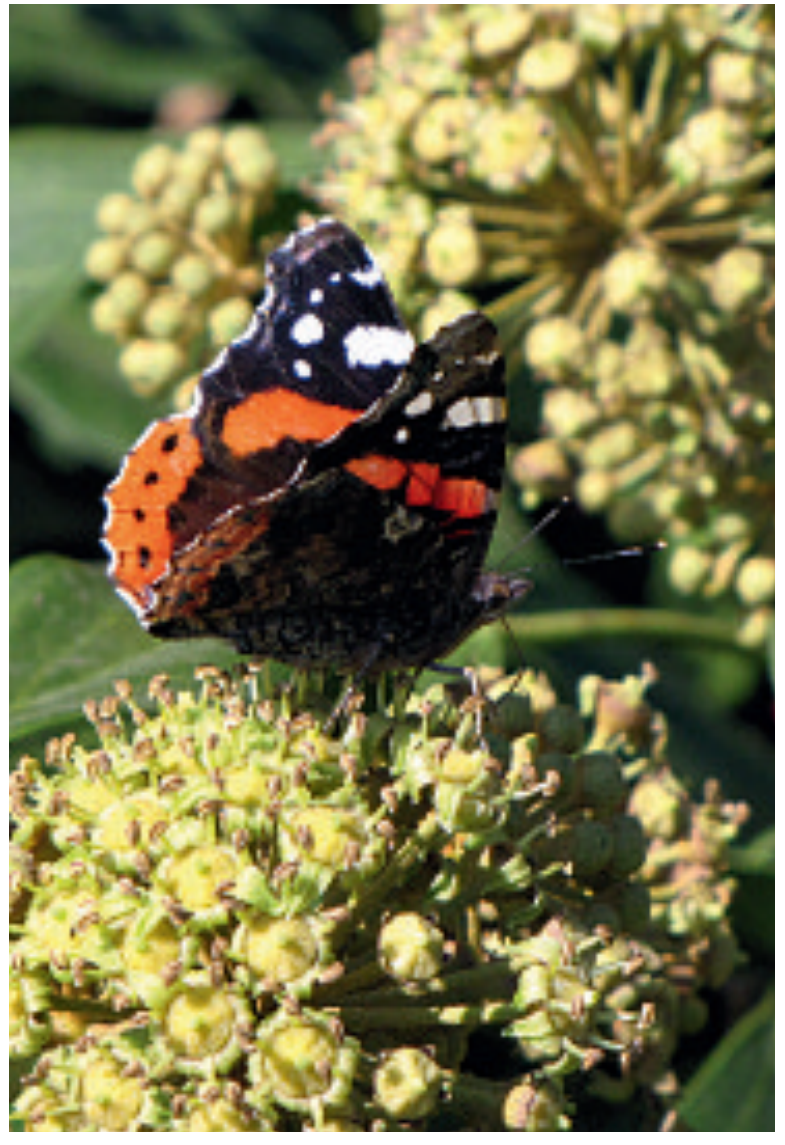

Wir hoffen, dass in Zukunft das lang ersehnte Schmetterlingshaus mit frei fliegenden tropischen Schmetterlingen im Palmengarten realisiert werden kann. Im Sommerhalbjahr können im Palmengarten aber auch draußen viele heimische Schmetterlinge beobachtet werden. Bevorzugte Anlagen sind dabei die Sommerblumenwiese und die Steppenanlage mit ihren vielen nektarreichen Wildarten sowie der buntblühende Sommerflor rund um das Tropicarium.

Abb. 1 (oben): Kleiner Fuchs auf dem Fruchtstand eines Wiesenbocksbartes.

Abb. 2 (unten): Admiral auf Efeublüten. 

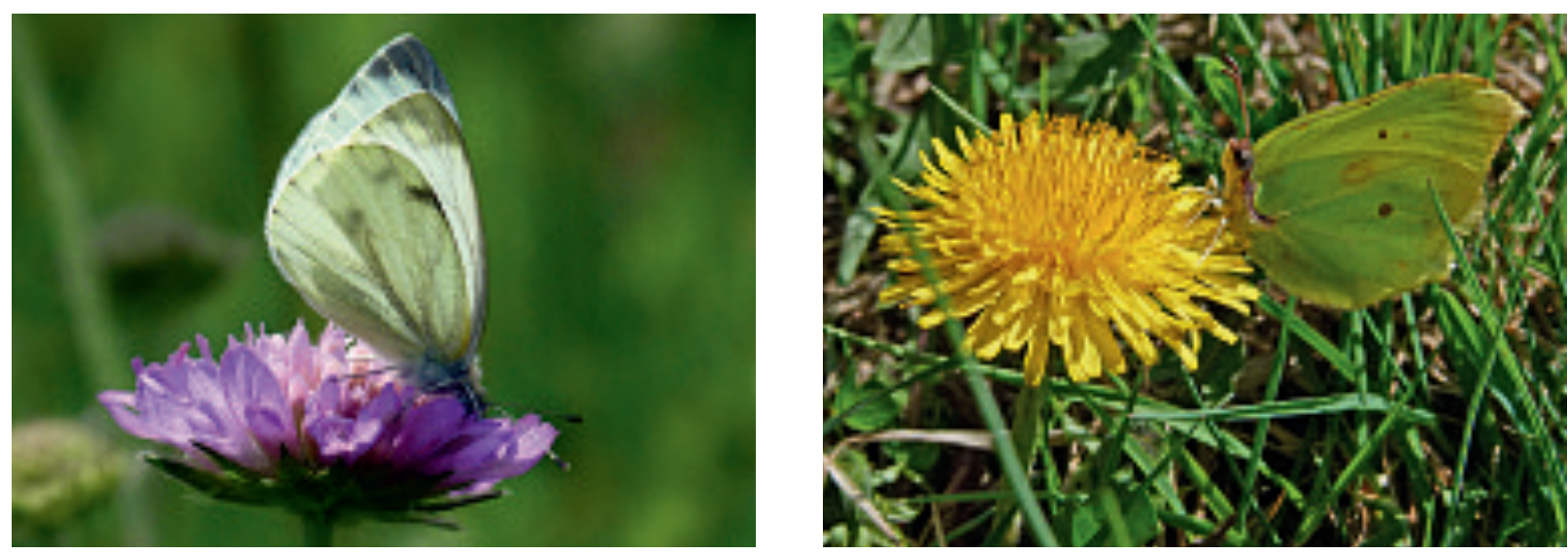

Abb. 3 (oben links): Großer Kohlweißling auf einer Acker-Witwenblume.

Abb. 4 (oben rechts): Zitronenfalter gehören zu den ersten Schmetterlingen des Jahres.

Abb. 5 (Mitte): Distelfalter im Sommerflor auf einer Zinnien-Blüte.

Abb. 6 (unten): Schwalbenschwanz saugt

Nektar an den Blüten der Karthäusernelke.
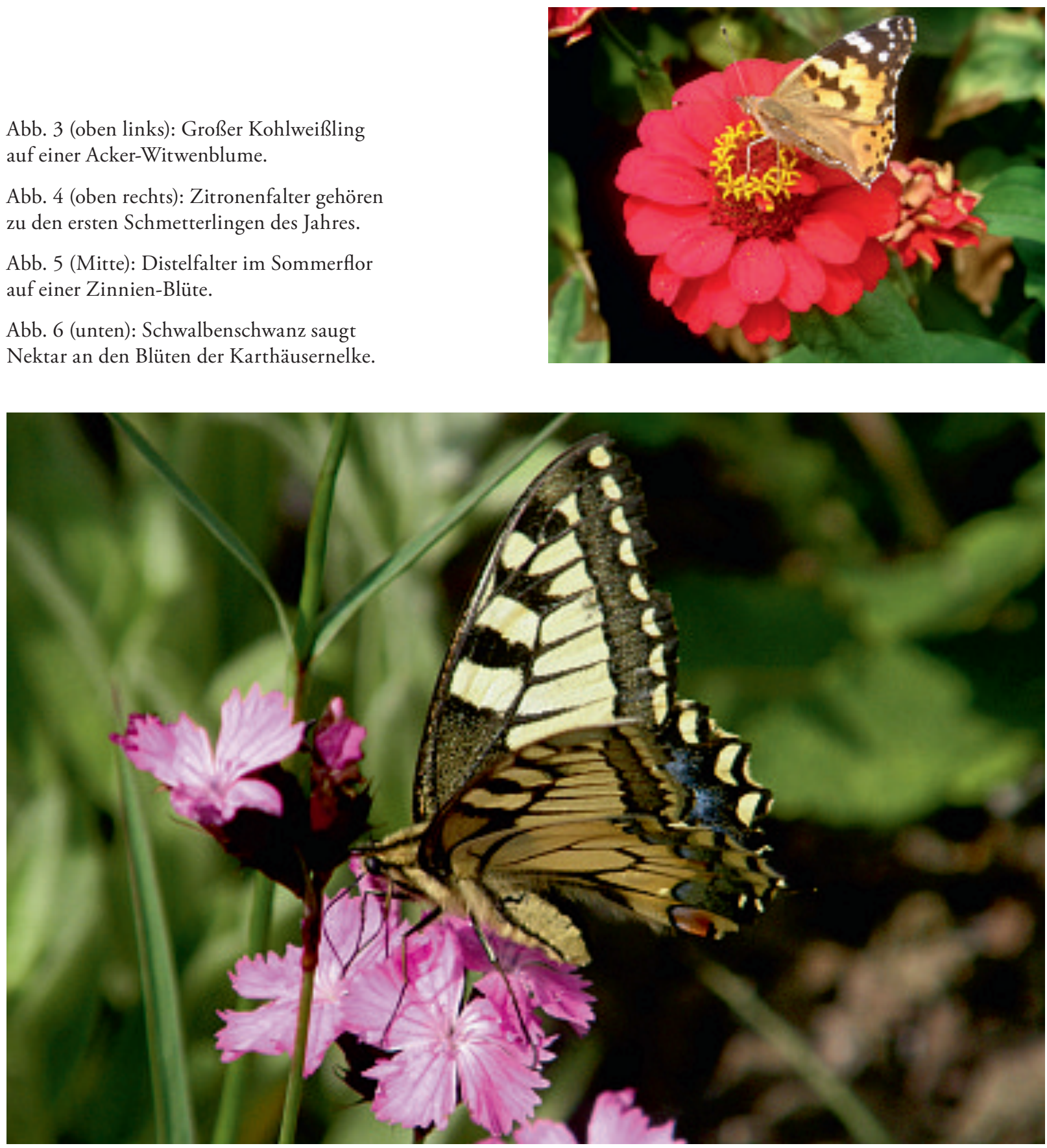